\title{
Analisis Profil TPACK Guru TIK SMA di Kecamatan Pontianak Kota
}

\author{
Vindo Feladi $^{\# 1}$, Henny Puspitasari ${ }^{\# 2}$

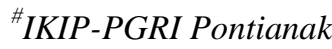 \\ Jalan Ampera No. 88 \\ ${ }^{1}$ vindo.feladi@gmail.com \\ ${ }^{2}$ henny078@gmail.com
}

\begin{abstract}
Abstrak- Penelitian ini mengenai pemahaman tentang kompetensi memadukan teknologi, cara mengajar atau pedagogic, dan materi ajar yang harus dimiliki seorang guru terutama dalam mengajarkan materi TIK. Metode dalam penelitian ini menggunakan pendekatan kualitatif yaitu dengan cara pengumpulan data, reduksi data, penyajian data dan kesimpulan yang diperoleh melalui wawancara. Pengumpulan dan penyusunan data melalui wawancara ini dilakukan dengan menggunakan interactive model. Teknik penentuan sampel menggunakan sampling jenuh. Penelitian ini dilakukan pada guru TIK di SMA Pontianak Kota dengan jumlah sampel 3 orang. Adapun simpulan hasil data kualitatif melalui pengumpulan data wawancara tiap responden adalah guru mengintegrasikan teknologi, pedagogi dan materi dengan cukup baik. Di dalam proses pembelajaran guru selalu memikirkan pembelajaran yang efektif dengan menggunakan fasilitas seperti komputer, proyektor dan internet di integrasikan menggunakan model pembelajaran yang cukup bervariasi yang disesuaikan dengan materi.
\end{abstract}

Kata Kunci-Guru, TPACK, TIK

\section{Pendahuluan}

Guru harus dapat menyampaikan informasi yang diketahuinya dengan benar dan tepat sasaran, yaitu konten materi yang benar melalui kegiatan pedagogis yang baik. Referensi [1] mendefinisikan subjek pengetahuan pengajaran konten materi sebagai pengetahuan konten dan pedagogik (PCK). Referensi [2] PCK adalah pengetahuan pedagogis yang berlaku untuk pengajaran konten yang spesifik. PCK meliputi pendekatan apa yang sesuai dengan konten atau dapat juga bagaimana elemen konten dapat diatur untuk pembelajaran yang lebih baik. Definisi PCK juga dikemukakan oleh [3], yaitu pengetahuan seorang guru dalam menyediakan situasi mengajar untuk membantu pembelajar dalam mengerti konten atas fakta ilmu pengetahuan.

Seorang guru yang memfasilitasi siswa untuk melakukan proses pembelajaran dengan menggunakan teknologi dapat memperkuat pemahaman konsep siswa dan melatih keterampilan ilmiah siswa. Referensi [4] berpendapat bahwa "Guru sebagai pendidik adalah tokoh yang paling banyak bergaul dan berinteraksi dengan para murid dibandingkan dengan personel lainnya di sekolah".

Pengetahuan tentang teknologi, pedagogik, dan konten telah menjadi bagian integral dari program pendidikan guru untuk mempersiapkan guru dimana mereka mengajar menggunakan teknologi dalam pengajaran. Berdasarkan referensi [1] telah menambahkan teknologi untuk PCK, dan menggambarkan Technologycal Pedagogical and Content Knowladge TPACK sebagai hubungan antara teknologi, pedagogik, dan konten. TPACK merupakan suatu bentuk pengetahuan yang kompleks dan sangat penting bagi guru, karena TPACK adalah pengetahuan yang dibutuhkan agar guru dapat menggunakan teknologi yang tepat, yang didasarkan pada analisis karakter materi dan analisis pada aspek pedagogi TPACK mensyaratkan adanya multi interaksi yang unik dan sinergi antara materi, pedagogi dan teknologi [5]. Referensi [5] TPACK terdiri atas enam komponen pengetahuan, seperti Technology Knowledge (TK), Content Knowledge (CK), Pedagogical Knowledge (PK), Pedagogical Content Knowledge (PCK), Technological Pedagogical Knowledge (TPK), dan Technological Content Knowledge (TCK).

Referensi [6] mendefinisikan Technology Knowledge (TK) adalah dasar-dasar teknologi yang dapat dimanfaatkan untuk mensupport pembelajaran. Content Knowledge (CK) adalah pengetahuan tentang materi pelajaran yang akan dipelajari. Pedagogical Knowledge (PK) menggambarkan pengetahuan secara mendalam terkait dengan teori dan praktik belajar mengajar yang mencakup tujuan, proses, metoda pembelajaran penilaian, strategi dan lainnya. Pedagogical Content Knowledge (PCK) mencakup interaksi dan terjadinya irisan antara pedagogi (P) dan materi pelajaran (C). Technological Pedagogical Knowledge (TPK) adalah merupakan serangkaian pemahaman bagaimana perubahan 
pembelajaran terjadi dengan memanfaatkan teknologi yang digunakan untuk mendukung pembelajaran secara aktif dan dapat membantu serta mempermudah konsepkonsep atau materi pelajaran. Technological Content Knowledge (TCK) termasuk dalam pemahaman teknologi dan materi pelajaran yang dapat membantu serta mempengaruhi komponen-komponen yang lain.

Hal ini sejalan dengan penelitian yang dilakukan oleh [7]. Hasil penelitian ini menunjukkan bahwa TPACK dan kemampuan menyusun perangkat pembelajaran calon guru fisika meningkat setelah diajar dengan menggunakan model pembelajaran POST-PACK.Referensi [8]bahwa : 1 . Tingkat kemampuan TPACK pada guru SMA dalam materi sistem saraf tidak berbanding lurus dengan lamanya pengalaman mengajar seorang guru, karena ternyata hasil dari analisis data menunjukkan tidak ada perbedaan antara kelompok 1 dan 2 dalam tingkat kemampuan TPACK. 2. Kemampuan perencanaan dan implementasi dari TPACK guru SMA baru sebatas penggunaan infokus dan perangkatnya beserta whiteboard, dan spidol yang diimplementasikan dalam proses kegiatan belajar mengajar dengan metode presentasi di kelas oleh masing-masing kelompok.

Referensi [9] guru memiliki gambaran PCK yang baik jiak hanya dilihat dari jawaban CoRes, sedangkan jawaban CoRes tidak tercermin dalam RPP atau pelaksanaan. Guru belum baik dalam hal perencanaan, dibuktikan dengan tidak adanya beberapa aspek CoRes dalam RPP. Ketiga guru dalam RPP umumnya melupakan aspek CoRes nomor 2, 3, 9, dan 10. Begitu pula dengan penilaian CoRes dalam pelaksanaan pembelajaran, ketiga guru melupakan aspek nilai penting, tujuan dan manfaat diajarkannya suatu konsep. PCK guru yang baik akan berkesinambungan antara nilai CoRes, CoRes dalam RPP dan CoRes dalam pelaksanaan pembelajaran. Namun, pada penelitian ini, hal tersebut belum tercapai. PCK guru akan berkaitan dengan penerimaan siswa, baik dari kemampuan siswa menerima dan mengolah informasi, usaha mental, dan hasil belajar. Hal tersebut masih dalam penelitian dan analisis lebih lanjut.

Referensi [10] menunjukkan (1) Pada kelompok mahasiswa calon guru dengan kemampuan akademik sangat baik dan kelompok mahasiswa calon guru dengan kemampuan akademik baik mempunyai pengetahuan konten, pengetahuan mengajar, dan pengetahuan siswa yang relatif sama. Pengetahuan konten sebagian besar berada pada level 1, pengetahuan mengajar berada pada level 2, dan pengetahuan siswa berada pada level 1, (2) Pada kelompok mahasiswa calon guru dengan kemampuan akademik cukup dapat disimpulkan bahwa pengetahuan konten berada pada level 0 , pengetahuan mengajar berada pada level 1, dan pengetahuan siswa berada pada level 1, dan (3) Pengetahuan konten pedagogis dari seseorang tidak hanya dipengaruhi oleh kemampuan akademiknya, tetapi dipengaruhi juga oleh pengalaman dan pelatihan tentang profesionalisme dan kemampuan pedagogis yang pernah diikuti.
Berdasarkan uraian diatas disimpulkan bahwa TPACK adalah sebuah konsep yang harus dimiliki oleh seorang guru sehingga guru memiliki potensi yang tidak hanya menyampaikan materi kepada siswa namun dapat mengintegrasikan teknologi, pedagogi dan materi. Untuk itu peneliti ingin mengetahui seberapa tinggi konsep TPACK yang dimiliki guru mata pelajaran Teknologi Informasi dan Komunikasi.

\section{TINJAUAN PUSTAKA}

Referensi [1] mendefinisikan subjek pengetahuan pengajaran konten materi sebagai pengetahuan konten dan pedagogik (PCK). Sedangkan menurut referensi [2] PCK adalah pengetahuan pedagogis yang berlaku untuk pengajaran konten yang spesifik. PCK meliputi pendekatan apa yang sesuai dengan konten atau dapat juga bagaimana elemen konten dapat diatur untuk pembelajaran yang lebih baik. Definisi PCK juga dikemukakan oleh [3], yaitu pengetahuan seorang guru dalam menyediakan situasi mengajar untuk membantu pembelajar dalam mengerti konten atas fakta ilmu pengetahuan.

Referensi [5] telah menambahkan teknologi untuk PCK, dan menggambarkan Technologycal Pedagogical and Content Knowladge TPACK sebagai hubungan antara teknologi, pedagogik, dan konten. TPACK merupakan suatu bentuk pengetahuan yang kompleks dan sangat penting bagi guru, karena TPACK adalah pengetahuan yang dibutuhkan agar guru dapat menggunakan teknologi yang tepat, yang didasarkan pada analisis karakter materi dan analisis pada aspek pedagogi TPACK mensyaratkan adanya multi interaksi yang unik dan sinergi antara materi, pedagogi dan teknologi [5]. Referensi [5] TPACK terdiri atas enam komponen pengetahuan, seperti Technology Knowledge (TK), Content Knowledge (CK), Pedagogical Knowledge (PK), Pedagogical Content Knowledge (PCK), Technological Pedagogical Knowledge (TPK), dan Technological Content Knowledge (TCK).

TPACK merupakan konsep yang harus dimiliki oleh seroang guru untuk mencapai suatu proses pembelajaran yang maksimal. Dimana dapat mengintegrasikan teknologi, pedagogi dan isi, yang diterapkan sesuai dengan konteks. Hal ini juga dimaknai sebagai bentuk pergasan pembelajaran yang semula terpusat pada guru bergeser kepada peserta belajar. Kerangka kerja yang dibutuhkan bagi guru adalah pemahaman efektivitas integrasi pembelajaran. TPACK menekankan hubungan hubungan antara teknologi, isi kurikulum dan pendekatan pedagogi yang berinteraksi satu sama lain untuk menghasilkan pembelajaran berbasis TIK. Referensi [5] juga menjelaskan bahwa pengajaran yang berkualitas membutuhkan nuansa pemahaman yang kompleks yang saling berhubungan diantara tiga sumber utama pengetahuan yaitu teknologi, pedagogi, dan isi, dan bagaimana ketiga sumber itu diterapkan sesuai dengan konteksnya [5]. 
Referensi [6] dengan judul “ Peranan TPACK terhadap Kemampuan Menyusun Perangkat Pembelajaran Calon Guru Fisika dalam Pembelajaran Post-Pack". Hasil penelitian ini menunjukkan bahwa TPACK dan kemampuan menyusun perangkat pembelajaran calon guru fisika meningkat setelah diajar dengan menggunakan model pembelajaran POST-PACK. Referensi [7] menunjukkan bahwa : 1. Tingkat kemampuan TPACK pada guru SMA dalam materi sistem saraf tidak berbanding lurus dengan lamanya pengalaman mengajar seorang guru, karena ternyata hasil dari analisis data menunjukkan tidak ada perbedaan antara kelompok 1 dan 2 dalam tingkat kemampuan TPACK. 2. Kemampuan perencanaan dan implementasi dari TPACK guru SMA baru sebatas penggunaan infokus dan perangkatnya yang diimplementasikan dalam proses kegiatan belajar mengajar dengan metode presentasi di kelas oleh masingmasing kelompok.

Referensi [8] menunjukkan secara umum guru memiliki gambaran PCK yang baik jiak hanya dilihat dari jawaban CoRes, sedangkan jawaban CoRes tidak tercermin dalam RPP atau pelaksanaan. Guru belum baik dalam hal perencanaan, dibuktikan dengan tidak adanya beberapa aspek CoRes dalam RPP. Ketiga guru dalam RPP umumnya melupakan aspek CoRes nomor 2, 3, 9, dan 10. Begitu pula dengan penilaian CoRes dalam pelaksanaan pembelajaran, ketiga guru melupakan aspek nilai penting, tujuan dan manfaat diajarkannya suatu konsep. PCK guru yang baik akan berkesinambungan antara nilai CoRes, CoRes dalam RPP dan CoRes dalam pelaksanaan pembelajaran. Namun, pada penelitian ini, hal tersebut belum tercapai. PCK guru akan berkaitan dengan penerimaan siswa, baik dari kemampuan siswa menerima dan mengolah informasi, usaha mental, dan hasil belajar. Hal tersebut masih dalam penelitian dan analisis lebih lanjut.

\section{METODE PENELITIAN}

\section{A. Jenis Penelitian}

Penelitian tentang "Analisis profil TPACK Guru TIK SMA di Kecamatan Pontianak Kota" menggunakan pendekatanpenelitian kualitatif. Penelitian kualitatif ini digunakan untuk menganalisis profil guru TIK SMA di Kecamatan Pontianak Kota.

\section{B. Desain Penelitian}

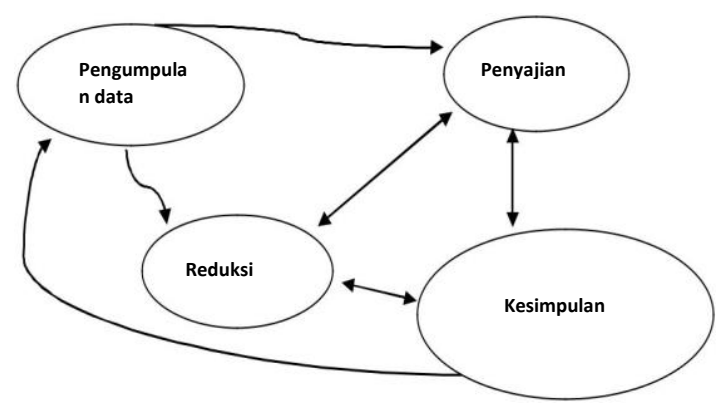

Gambar 1. Rancangan Penelitian
Rancangan penelitian pada gambar 1 dapat dijelaskan sebagai berikut:

\section{1) Pengumpulan Data}

Pengumpulan data dari hasil wawancara guru TIK di Kecamatan Pontianak Kota yang mencakup penggunaan teknologi, kemampuan mengajar dan kemampuan menguasai materi TIK.

\section{2) Reduksi Data}

Mereduksi data berarti merangkum, memilih hal-hal yang pokok, memfokuskan pada hal-hal yang penting, di cari tema dan polanya dan membuang yang tidak perlu. Dengan demikian data yang telah direduksi akan memberikan gambaran yang jelas dan mempermudah peneliti untuk melakukan pengumpulan data selanjutnya dan mencarinya bila diperlukan.

\section{3) Penyajian Data}

Setelah data direduksi, maka langkah selanjutnya adalah mendisplaykan data atau menyajikan data. Dalam penelitian ini penyajian data dilakukan dengan uraian singkat yang bersifat naratif. Dengan mendisplay data, maka akan memudahkan untuk memahami apa yang terjadi, merencanakan kerja selanjutnya berdasarkan apa yang telah dipahami.

\section{4) Kesimpulan}

Langkah ketiga yaitu penarikan kesimpulan dan verifikasi. Kesimpulan awal yang dikemukakan masih bersifat sementara dan akan berubah apabila tidak ditemukan bukti-bukti yang kuat yang mendukung pada tahap pengumpulan data selanjutnya. Tetapi apabila kesimpulan yang dikemukakan pada tahap awal, didukung oleh bukti-bukti yang valid saat peneliti kembali ke lapangan mengumpulkan data, maka kesimpulan yang dikemukakan merupakan kesimpulan yang kredibel.

\section{Populasi dan Sampel}

Populasi dalam penelitian ini adalah guru mata pelajaran TIK SMA sepontianak kota yang tersebar di 10 Sekolah. Teknik penarikan sampel yang digunakan dalam penelitian ini adalah teknik purposive samPling. Oleh karena itu sekolah yang dijadikan sampel dalam penelitian ini adalah SMAS Rahadi Oesman Pontianak, SMAS Wali Songo Pontianak, dan SMA Islam Al-Baisuny.

\section{Teknik Pengumpulan Data}

Teknik yang digunakan dalam penelitian ini adalah komunikasi tak langsung, komunikasi langsung dan studi dokumenter. Alat pengumpulan data yang digunakan adalah angket, pedoman wawancara dalam penelitian ini berupa data profil guru TIK setiap sekolah serta audio dari hasil wawancara guru TIK. 
IV. HASIL

Untuk deskripsi data yang lebih rinci dapat dilihat dalam uraian data pada Tabel 1 di bawah ini:

TABEL 1

HASIL DATA KUALITATIF TECHNOLOGICAL KNOWLEDGE (TK)

\begin{tabular}{|c|c|c|}
\hline No & $\begin{array}{l}\text { Aspek Minat } \\
\text { yang diukur }\end{array}$ & Hasil Kualitatif \\
\hline 1 & $\begin{array}{l}\text { Mengetahui } \\
\text { mengatasi } \\
\text { masalah } \\
\text { teknis pada } \\
\text { komputer }\end{array}$ & $\begin{array}{l}\text { Tergantung kerusakan Jika dapat } \\
\text { diperbaiki sendiri maka guru TIK } \\
\text { memperbaikinya sendiri. Jika } \\
\text { kerusakannya parah maka di bawa ke } \\
\text { toko service komputer }\end{array}$ \\
\hline 2 & $\begin{array}{l}\text { Mudah untuk } \\
\text { belajar } \\
\text { menggunakan } \\
\text { teknologi }\end{array}$ & $\begin{array}{l}\text { Guru sangat memahami penggunaan } \\
\text { teknologi seperti komputer, internet dan } \\
\text { lainnya. Teknologi sangat membantu } \\
\text { untuk memenuhi kebutuhan sehari-hari, } \\
\text { dan memudahkan pekerjaan }\end{array}$ \\
\hline 3 & $\begin{array}{l}\text { Mengikuti } \\
\text { perkembanga } \\
\text { n teknologi } \\
\text { terbaru }\end{array}$ & $\begin{array}{l}\text { Guru selalu mengikuti perkembangan } \\
\text { tekenologi, tetapi guru menggunakan } \\
\text { teknologi yang biasa mereka gunakan, } \\
\text { karena sudah merasa nyaman dan } \\
\text { mudah dalam menggunakannya }\end{array}$ \\
\hline 4 & $\begin{array}{l}\text { Pemahaman } \\
\text { mengenai } \\
\text { komponen } \\
\text { dasar } \\
\text { computer }\end{array}$ & $\begin{array}{l}\text { Guru sangat memahami mengenai } \\
\text { komponen dasar komputer. Baik segi } \\
\text { input, process dan output }\end{array}$ \\
\hline 5 & $\begin{array}{l}\text { Mahir } \\
\text { menggunakan } \\
\text { program } \\
\text { pengolah kata }\end{array}$ & $\begin{array}{l}\text { Guru sangat menguasai aplikasi } \\
\text { Microsoft office word. Namun yang } \\
\text { paling sering digunakan yaitu office } \\
\text { word } 2007\end{array}$ \\
\hline 6 & $\begin{array}{l}\text { Mahir } \\
\text { menggunakan } \\
\text { program } \\
\text { pengolah } \\
\text { angka }\end{array}$ & $\begin{array}{l}\text { Guru sangat menguasai dalam } \\
\text { penggunaan microsfot office excel, guru } \\
\text { sering menggunakan aplikasi office } \\
\text { excel seperti untuk input nilai siswa, dan } \\
\text { sebagai salah satu aplikasi yang di } \\
\text { ajarkan kepada peserta didik. Namun } \\
\text { yang paling sering digunakan yaitu ms } \\
\text { office excel } 2007\end{array}$ \\
\hline 7 & $\begin{array}{l}\text { Mahir } \\
\text { menggunakan } \\
\text { program } \\
\text { presentasi }\end{array}$ & $\begin{array}{l}\text { Guru mahir menggunakan aplikasi } \\
\text { office power point namun guru jarang } \\
\text { menggunakannya dikarenakan tidak bisa } \\
\text { untuk dipersentasikan karena alat yang } \\
\text { tidak mendukung. Selain itu ada guru } \\
\text { yang tidak membuat bahan persentase } \\
\text { karena sudah terbiasa menggunakan } \\
\text { metode ceramah menggunakan LKS }\end{array}$ \\
\hline 8 & $\begin{array}{l}\text { Mahir } \\
\text { menggunakan } \\
\text { printer, } \\
\text { scanner, } \\
\text { projector dan } \\
\text { digital camera }\end{array}$ & $\begin{array}{l}\text { Guru cukup memahami penggunaan alat } \\
\text { seperti printer, scanner dan digital } \\
\text { cemera. Karena mereka juga sering } \\
\text { menggunakannya }\end{array}$ \\
\hline 9 & $\begin{array}{l}\text { Menyimpan } \\
\text { data-data } \\
\text { pada media } \\
\text { digital }\end{array}$ & $\begin{array}{l}\text { Guru jarang menyimpan data mereka } \\
\text { pada media digital, seperti ziddu.com, } \\
\text { google drive dn skydrive. Karena } \\
\text { mereka merasa lebih simple jika } \\
\text { meyimpan data di flashdisk, hardisk } \\
\text { atau computer }\end{array}$ \\
\hline 10 & $\begin{array}{l}\text { Menggunakan } \\
\text { internet } \\
\text { sebagai media } \\
\text { komunikasi }\end{array}$ & $\begin{array}{l}\text { Guru selalu menggunakan media } \\
\text { internet sebagai media komunikasi. } \\
\text { Karena bagi mereka internet adalah } \\
\text { suatu kebutuhan pada zaman sekarang } \\
\text { ini dan dmna saja, kapan saja } \\
\text { komunikasi menjadi cepat. Jika sudah } \\
\text { kebutuhan maka kita tidak akan bisa } \\
\text { terlepas dari namaya internet. Karena } \\
\text { kita sudah terbiasa akan hal ini }\end{array}$ \\
\hline
\end{tabular}

Berdasarkan Tabel 1 hasil analisis data kualitatif melalui metode wawancara adalah guru memperbaiki komputer tergantung kerusakan jika dapat diperbiki sendiri maka guru TIK memperbaikinya sendiri. Jika kerusakannya parah maka di bawa ke toko service komputer.

TABEL 2

HASIL DATA KUALITATIF CONTENT KNOWLEDGE (CK)

\begin{tabular}{|c|c|c|}
\hline No & $\begin{array}{c}\text { Aspek Minat yang } \\
\text { diukur }\end{array}$ & Hasil Kualitatif \\
\hline 1 & $\begin{array}{l}\text { Memahami konsep, } \\
\text { teori TIK serta } \\
\text { penerapannya secara } \\
\text { fleksibel }\end{array}$ & $\begin{array}{l}\text { Guru sangat menguasai } \\
\text { materi dan pada saat proses } \\
\text { pembelajaran guru } \\
\text { melakukan dengan berbagai } \\
\text { cara yang dapat membuat } \\
\text { peserta didiknya tidak } \\
\text { merasa bosan di kelas } \\
\text { maupun di lab. Seperti guru } \\
\text { melakukan pendekatan } \\
\text { terlebih dahulu sebelum saat } \\
\text { proses pembelajaran dimulai } \\
\text { agar siswa nya tidak tegang. } \\
\text { Selain itu guru juga } \\
\text { memberikan tugas kepada } \\
\text { siswa berupa materi kepada } \\
\text { siswa kemudian setelah itu } \\
\text { didiskusikan secara bersama }\end{array}$ \\
\hline 2 & $\begin{array}{l}\text { Mengetahui sejarah } \\
\text { dan perkembangan } \\
\text { teknologi komputer } \\
\text { khususnya pada TIK }\end{array}$ & $\begin{array}{l}\text { Guru sangat mengetahui } \\
\text { perkembangan teknologi } \\
\text { namun tidak selalu teknologi } \\
\text { terbaru yang digunakan. } \\
\text { Tapi kita sebagai orang TIK } \\
\text { harus selalu mengikuti atau } \\
\text { mengetahui di setiap } \\
\text { perkembangan teknologi. } \\
\text { Karena perkembangan } \\
\text { teknologi sangat cepat }\end{array}$ \\
\hline 3 & $\begin{array}{l}\text { Menggunakan } \\
\text { sumber terbaru } \\
\text { (seperti buku, jurnal) } \\
\text { untuk menambah } \\
\text { ilmu TIK }\end{array}$ & $\begin{array}{l}\text { Guru juga kadang-kadang } \\
\text { menggunakan sumber buku } \\
\text { untuk menambah referensi } \\
\text { materi TIK. Selain itu guru } \\
\text { juga ada yang membuat } \\
\text { modul sendiri }\end{array}$ \\
\hline 4 & $\begin{array}{l}\text { Mengikuti seminar } \\
\text { atau kegiatan yang } \\
\text { berkaitan dengan } \\
\text { TIK }\end{array}$ & $\begin{array}{l}\text { Guru pernah melakukan } \\
\text { kegiatan-kegiatan yang } \\
\text { berkaian dengan TIK }\end{array}$ \\
\hline
\end{tabular}

Berdasarkan tabel 2 hasil analisis data melalui wawancara yaitu guru sangat menguasai materi dan pada saat proses pembelajaran guru melakukan dengan berbagai cara yang dapat membuat peserta didiknya tidak merasa bosan di kelas maupun di lab. Seperti guru melakukan pendekatan terlebih dahulu sebelum saat proses pembelajaran dimulai agar siswa nya tidak tegang. Selain itu guru juga memberikan tugas kepada siswa berupa materi kepada siswa kemudian setelah itu didiskusikan secara bersama. 
TABEL 3

Hasil DATA KUALITATIF PEDAGOGICAL KNOWLEDGE (PK)

\begin{tabular}{|c|c|c|}
\hline No & Aspek Minat yang diukur & Hasil Kualitatif \\
\hline 1 & $\begin{array}{l}\text { Memiliki pengetahuan } \\
\text { dalam mengembangkan } \\
\text { perangkat pembelajaran }\end{array}$ & $\begin{array}{l}\text { Guru sangat menguasai dalam } \\
\text { pembuatan perangkat } \\
\text { permbelajaran. Guru juga sering } \\
\text { dalam membuat perangkat } \\
\text { pembelajaran seperti RPP, karena } \\
\text { guru merasa sangat mudah jika } \\
\text { dalam menyampaikan sebuah } \\
\text { materi di sajikan atau di susun } \\
\text { terlebih dahulu dalam RPP }\end{array}$ \\
\hline 2 & $\begin{array}{l}\text { Memahami bermacam- } \\
\text { macam model } \\
\text { pembelajaran yang } \\
\text { bervariasi }\end{array}$ & $\begin{array}{l}\text { Guru berpendapat bahwa } \\
\text { pembelajaran yang bervariasi } \\
\text { memang sangat dibutuhkan agar } \\
\text { siswa tidak merasa bosan. Maka } \\
\text { salah satu nya adalah dengan } \\
\text { melakukan pembelajaran yang } \\
\text { santai, diskusi, praktek sambil } \\
\text { mendengarkan musik, dan guru } \\
\text { juga sering melakukan } \\
\text { pembelajaran dengan metode } \\
\text { pembelajaran yang berbeda }\end{array}$ \\
\hline 3 & $\begin{array}{l}\text { Memiliki pengetahuan } \\
\text { mengenai metode dan } \\
\text { teknik penilaian yang } \\
\text { bervariasi }\end{array}$ & $\begin{array}{l}\text { Guru sering melakukan penilaian } \\
\text { dengan memberikan soal pilihan } \\
\text { ganda atau essay yang ada di } \\
\text { LKS, namun selain itu penilaian } \\
\text { keaktifan dan keterampilan siswa } \\
\text { juga di lihat }\end{array}$ \\
\hline 4 & $\begin{array}{l}\text { Memiliki pengetahuan } \\
\text { dan mengelola kelas } \\
\text { dengan baik dalam } \\
\text { praktek pembelajaran }\end{array}$ & $\begin{array}{l}\text { Cara yang dilakukan guru dalam } \\
\text { praktek pembelajaran yaitu } \\
\text { menjelaskan kepada siswa } \\
\text { mengenai materi yang akan } \\
\text { disampaikan menggunakan bahan } \\
\text { persentasi berupa power point } \\
\text { dan menggunakan proyektor. } \\
\text { selain itu guru memberikan } \\
\text { kebebasan pada siswa untuk } \\
\text { berimajinasi sendiri apabila } \\
\text { praktek mengenai materi desain } \\
\text { menggunakan aplikasi coreldraw, } \\
\text { kemudian guru juga memberikan } \\
\text { kebebasan kepada siswa untuk } \\
\text { sambil mendengarkan musik. } \\
\text { Namun sekolah yang tidak } \\
\text { memiliki lab kom maka praktek } \\
\text { pembelajaran dilakukan secara } \\
\text { bergantian menggunakan } 1 \text { laptop }\end{array}$ \\
\hline
\end{tabular}

Berdasarkan tabel 3 hasil analisis data melalui wawancara yaitu guru sangat menguasai dalam pembuatan perangkat permbelajaran. Guru juga sering dalam membuat perangkat pembelajaran seperti RPP, karena guru merasa sangat mudah jika dalam menyampaikan sebuah materi di sajikan atau di susun terlebih dahulu dalam RPP.

Berdasarkan tabel 4 hasil analisis data melalui wawancara yaitu cara yang dilakukan guru dalam praktek pembelajaran yaitu Guru melakukan pendekatan terlebih dahulu dengan siswa dan kemudian di kaitkan dengan materi yang disampaikan selain itu guru juga memikirkan strategi yang benar dan bervariasi sesuai dengan materi yang disampaikan sehingga siswa dapat lebih fokus dan santai dalam menerima ilmu yang disampaikan oleh guru.
TABEL 4

Hasil DAta KUAlitatif Pedagogical CONTENT KNOWLEDGE(PCK)

\begin{tabular}{|c|c|c|}
\hline No & Aspek Minat yang diukur & Hasil Kualitatif \\
\hline 1 & $\begin{array}{l}\text { Memilih pendekatan dan } \\
\text { strategi pembelajaran yang } \\
\text { sesuai dengan materi TIK yang } \\
\text { ada }\end{array}$ & $\begin{array}{l}\text { Guru melakukan } \\
\text { pendekatan terlebih dahulu } \\
\text { dengan siswa dan } \\
\text { kemudian di kaitkan } \\
\text { dengan materi yang } \\
\text { disampaikan selain itu } \\
\text { guru juga memikirkan } \\
\text { strategi yang benar dan } \\
\text { bervariasi sesuai dengan } \\
\text { materi yang disampaikan } \\
\text { sehingga siswa dapat lebih } \\
\text { fokus dan santai dalam } \\
\text { menerima ilmu yang } \\
\text { disampaikan oleh guru }\end{array}$ \\
\hline 2 & Memperisapkan RPP sendiri & $\begin{array}{l}\text { Guru selalu } \\
\text { mempersiapkan RPP } \\
\text { sendiri }\end{array}$ \\
\hline
\end{tabular}

TABEL 5

Hasil data KUALITATIFTECHNOLOGICAL PEDAGOGICAL KNOWLEDGE (TPK)

\begin{tabular}{|c|c|c|}
\hline \multicolumn{3}{|r|}{$(1 \mathrm{~N})$} \\
\hline No & $\begin{array}{l}\text { Aspek Minat } \\
\text { yang diukur }\end{array}$ & Hasil Kualitatif \\
\hline 1 & $\begin{array}{l}\text { Menggunakan } \\
\text { aplikasi komputer } \\
\text { (Microsoft word, } \\
\text { Power point) } \\
\text { dalam } \\
\text { pembelajaran/prak } \\
\text { tek mengajar }\end{array}$ & $\begin{array}{l}\text { Guru sering menggunakan } \\
\text { aplikasi ms office power point } \\
\text { dan office word pada saat } \\
\text { pembelajaran praktek maupun di } \\
\text { kelas }\end{array}$ \\
\hline 2 & $\begin{array}{l}\text { Memilih teknologi } \\
\text { yang sesuai } \\
\text { dengan } \\
\text { pendekatan dan } \\
\text { strategi } \\
\text { pembelajaran } \\
\text { pada praktek } \\
\text { pembelajaran }\end{array}$ & $\begin{array}{l}\text { Guru kadang-kadang } \\
\text { menggunakan power point dalam } \\
\text { menyampaikan materi, kemudian } \\
\text { guru juga menggunakan media } \\
\text { yang sesuai dengan materi yang } \\
\text { akan disampaikan. Jika pada saat } \\
\text { ingin mempersentasikan materi } \\
\text { maka menggunakan bahan } \\
\text { persentasi dan proyektor untuk di } \\
\text { persentasi (bagi sekolah yang } \\
\text { punya LAB KOM), guru juga } \\
\text { menggunakan aplikasi ms office } \\
\text { excel jika materi nya menganai } \\
\text { pengoperasian excel }\end{array}$ \\
\hline 3 & $\begin{array}{l}\text { Menggunakan } \\
\text { fasilitas internet } \\
\text { (seperti social } \\
\text { media, blog untuk } \\
\text { media } \\
\text { pembelajaran) }\end{array}$ & $\begin{array}{l}\text { Guru jarang menggunakan } \\
\text { fasilitas internet sebagai media } \\
\text { untuk pembelajaran. karena di } \\
\text { sekolah ada yang tidak memiliki } \\
\text { akses internet }\end{array}$ \\
\hline
\end{tabular}

Berdasarkan tabel 5 hasil analisis data melalui wawancara yaitu guru sering menggunakan aplikasi ms office power point dan office word pada saat pembelajaran praktek maupun di kelas. Jika pada saat ingin mempersentasikan materi maka menggunakan bahan persentasi dan proyektor untuk di persentasi (bagi sekolah yang punya LAB KOM), guru juga menggunakan aplikasi ms office excel jika materi nya menganai pengoperasian excel. 
TABEL 6

Hasil DATA KUALiTATIF TECHNOLOGICAL CONTENT KNOWLEDGE (TCK)

\begin{tabular}{|c|c|c|}
\hline No & $\begin{array}{c}\text { Aspek Minat yang } \\
\text { diukur }\end{array}$ & Hasil Kualitatif \\
\hline 1 & $\begin{array}{l}\text { Menggunakan } \\
\text { teknologi untuk } \\
\text { membantu } \\
\text { memahami konsep, } \\
\text { dan teori TIK }\end{array}$ & $\begin{array}{l}\text { Guru menggunakan } \\
\text { teknologi sebagai } \\
\text { upaya agar siswa } \\
\text { lebih mudah } \\
\text { memahami materi. } \\
\text { Guru memberikan } \\
\text { media pembelajaran } \\
\text { berupa video, maka } \\
\text { siswa akan lebih } \\
\text { santai dan mudah } \\
\text { memahami materi } \\
\text { tersebut }\end{array}$ \\
\hline 2 & $\begin{array}{l}\text { Mengetahui } \\
\text { aplikasi-aplikasi } \\
\text { Komputer yang } \\
\text { berakaitan dengan } \\
\text { TIK }\end{array}$ & $\begin{array}{l}\text { Guru mengetahui } \\
\text { aplikasi-aplikasi } \\
\text { komputer kemudian } \\
\text { juga digunakan saat } \\
\text { proses } \\
\text { pembelajaran. } \\
\text { seperti } \\
\text { pembelajaran MS } \\
\text { Office Power Point, } \\
\text { Excel dan } \\
\text { coreldraw }\end{array}$ \\
\hline 3 & $\begin{array}{l}\text { Memiliki } \\
\text { pengetahuan dalam } \\
\text { mengembangkan } \\
\text { aktivitas dan tugas } \\
\text { siswa yang } \\
\text { melibatkan } \\
\text { peggunaan } \\
\text { teknologi }\end{array}$ & $\begin{array}{l}\text { Tugas yang } \\
\text { diberikan kepada } \\
\text { siswa adalah } \\
\text { mencari referensi di } \\
\text { internet. Kemudian } \\
\text { di persentasikan } \\
\text { dan didiskusikan } \\
\text { bersama. Dan } \\
\text { membuat video } \\
\text { pembelajaran }\end{array}$ \\
\hline
\end{tabular}

Berdasarkan tabel 6 hasil analisis data melalui wawancara yaitu guru menggunakan teknologi sebagai upaya agar siswa lebih mudah memahami materi. Guru memberikan media pembelajaran berupa video, maka siswa akan lebih santai dan mudah memahami materi tersebut. Mempelajajari aplikasi komputer itu memang sangat penting.

Berdasarkan tabel 7 hasil analisis data melalui wawancara yaitu bagi sekolah yang memiliki Lab guru sering menggunakan proyektor dan laptop sebagai media untuk mempersentasikan materi yang akan disampaikan. Namun bagi sekolah yang tidak memiliki Lab maka proyektor jarang gunakan. Praktek dilakukan dengan secara bergantian kedepan.
TABEL 7

Hasil data KUALITATIF TeChNOLOGICAL PEDAGOgICAL AND CONTENT KNOWLEDGE (TPACK)

\begin{tabular}{|c|c|c|}
\hline No & Aspek Minat yang diukur & Hasil Kualitatif \\
\hline 1 & $\begin{array}{l}\text { Memilih strategi } \\
\text { pembelajaran dan } \\
\text { teknologi yang sesuai } \\
\text { dengan materi TIK yang } \\
\text { akan disampaikan pada } \\
\text { kegiatan praktek } \\
\text { pembelajaran }\end{array}$ & $\begin{array}{l}\text { Bagi sekolah yang } \\
\text { memiliki Lab guru } \\
\text { sering menggunakan } \\
\text { proyektor dan laptop } \\
\text { sebagai media untuk } \\
\text { mempersentasikan } \\
\text { materi yang akan } \\
\text { disampaikan. Namun } \\
\text { bagi sekolah yang tidak } \\
\text { memiliki Lab maka } \\
\text { proyektor jarang } \\
\text { gunakan. Praktek } \\
\text { dilakukan dengan secara } \\
\text { bergantian kedepan }\end{array}$ \\
\hline 2 & $\begin{array}{l}\text { Memadukan } \\
\text { pengetahuan TIK, } \\
\text { pengetahuan pedagogik, } \\
\text { dan pengetahuan } \\
\text { teknologi yang dimiliki } \\
\text { untuk mewujudkan } \\
\text { pembelajaran yang } \\
\text { efektif }\end{array}$ & $\begin{array}{l}\text { Agar menjadikan } \\
\text { pembelajaran yang } \\
\text { efektif maka diperlukan } \\
\text { cara atau metode yang } \\
\text { sesuai dengan materi } \\
\text { yang akan disampaaikan } \\
\text { kemudian praktek juga } \\
\text { sangat diperlukan. Maka } \\
\text { jika } 3 \text { hal ini } \\
\text { digabungkan dan } \\
\text { dilaksanakan dengan } \\
\text { benar akan } \\
\text { menghasilkan tujuan } \\
\text { pembelajaran yang } \\
\text { efektif dan interaktif }\end{array}$ \\
\hline 3 & $\begin{array}{l}\text { Membantu teman saya } \\
\text { untuk memahami cara } \\
\text { pengintegrasian } \\
\text { pengetahuan TIK, } \\
\text { pengetahuan pedagogik, } \\
\text { dan pengetahuan } \\
\text { teknologi }\end{array}$ & $\begin{array}{l}\text { Guru saling bekerjasama } \\
\text { dan berkomunikasi } \\
\text { dengan guru lain dalam } \\
\text { pengintegrasian antara } \\
\text { materi, pedagogi dan } \\
\text { teknologi. Karena ketiga } \\
\text { hal ini sangat diperlukan } \\
\text { dalam proses } \\
\text { pembelajaran. jika tidak } \\
\text { adanya pedagogik atau } \\
\text { cara atau metode yang } \\
\text { dilakukan guru maka } \\
\text { pembelajaran pun } \\
\text { menjadi tidak efektif dan } \\
\text { siswa merasa bosan }\end{array}$ \\
\hline 4 & $\begin{array}{l}\text { Menerapkan strategi } \\
\text { pembelajaran yang } \\
\text { berbeda dan } \\
\text { menggunakan aplikasi } \\
\text { komputer yang bervariasi } \\
\text { dalam pelaksanaan } \\
\text { praktek pembelajaran }\end{array}$ & $\begin{array}{l}\text { Dalam pembelajaran } \\
\text { praktek guru tidak selalu } \\
\text { menggunakan strategi } \\
\text { yang baru atau yang } \\
\text { bervariasi }\end{array}$ \\
\hline
\end{tabular}




\section{KESIMPULAN}

Berdasarkan dari pengolahan data hasil penelitian, secara umum dapat disimpulakan bahwa Analisis Profil Technological Pedagogical and Content Knowledge (TPACK) guru TIK SMA di Kecamatan Pontianak Kota memperoleh hasil dengan kategori tinggi. Hal ini menunjukkan bahwa guru mampu mengintegrasikan teknologi, pedagogi dan materi kedalam proses pembelajaran mereka.

Guru mengintegrasikan teknologi, pedagogi dan materi dengan cukup baik. Didalam proses pembelajaran guru selalu memikirkan pembelajaran yang efektif dengan menggunakan fasilitas seperti komputer, proyektor dan internet di integrasikan menggunakan model pembelajaran yang cukup bervariasi yang disesuaikan dengan materi.

\section{UCAPAN TERIMA KASIH}

Peneliti mengucapkan terima kasih kepada:

1. RISTEK DIKTI sebagai atas bantuan dana pada skim Penelitian Dosen Pemula tahun 2017.

2. Sekolah Menengah Atas di Kecamatan Pontianak Kota.

3. JEPIN atas review jurnal pada penelitian ini.

\section{REFERENSI}

[1] Shulman. Knowledge and Teaching: Foundations Of The New Reform. Harvard Educational Review. 57 (1). 1987. pp 1 - 22

[2] Suryawati, E., Firdaus, L.N., \& Yosua, H. Analisis Keterampilan Technological Pedagogical Content Knowledge (TPCK) Guru Biologi SMA Negeri Kota Pekanbaru. Jurnal Biogenesis. Vol.11. No.1. 2014.pp 67-72.

[3] Loughran. Pedagogy Making Sense of the Complex Relationship Between Teaching And Learning. Curriculum Inquiry vol. 43 . No.1. 2013

[4] Sagala, Syaiful. Kemampuan Profesional Guru dan Tenaga Kependidikan. Bandung: Alfabeta. 2009

[5] Mishra, P., \& Koehler, M. J. Technological Pedagogical Content Knowledge: A new framework for teacher knowledge. Teachers College Record 108 (6), 1017-1054. 2006

[6] Sutrisno. Pengantar Pembelajaran Inovatif Berbasis Teknologi Informasi dan Komunikasi. Jakarta: Gaung Persada. 2011

[7] Sholihah, M., Yuliati, L., \& Wartono. Peranan tpack terhadap kemampuan calon guru fisika dalam pembelajaran post-pack Jurnal Pendidikan: Teori, Enelitian, Dan Pengembangan, 1(2), 144-153. 2016

[8] Suci Lestari. Analisis Kemampuan Technological Pedagogical Content Knowledge (TPACK) pada Guru Biologi SMA dalam Materi Sistem Saraf. Prosiding. pp 557-564. 2016

[9] Yeni Rahmadhani, Adi Rahmat dan Widi Purwianingsih. Pedagogical Content Knowledge (PCK) Guru dalam Pembelajaran Biologi SMA di Kota Cimahi. Jurnal Edukasi. Vol 7. No 17. 2016

[10] Maryono. Profil pedagogical content knowledge (pck) mahasiswa calon guru matematika ditinjau dari kemampuan akademiknya. Jurnal Riview Pembelajaran Matematika. Vol 1. No.16. 2016 